\title{
TMO beoordeeld: resultaten van het lezersonderzoek 2003
}

J.C.C. Borleffs, namens de redactie

\section{Samenvatting}

Inleiding: $N a$ veranderingen in het formaat van het Tijdschrift voor Medisch Onderwijs (TMO), de frequentie van verschijning, de opmaak, de omslag en de beoordelingsprocedure bestond er de behoefte de gevolgen daarvan te evalueren.

Materiaal en methoden: In het najaar van 2003 heeft een lezersonderzoek plaatsgevonden. Hiervoor kregen alle abonnees van TMO een vragenlijst toegestuurd met 22 vragen over het lezersprofiel, het soort informatie dat de lezer in TMO zoekt, het leesgedrag, de waardering voor TMO als lezer en de waardering voor TMO als tijdschrift om als auteur in te publiceren.

Resultaten: 254 van de 748 verstuurde vragenlijsten zijn teruggestuurd. Met een gemiddeld 'rapportcijfer' van 7.1 is de waardering voor TMO in het algemeen groot. De meeste lezers vinden TMO informatief en vinden de inhoud toepasbaar in de praktijksituatie, voldoende diepgaand en vernieuwend. Verreweg het grootst is de belangstelling voor onderwijskundig onderzoek, onderwijsvernieuwing, de medisch specialistenopleiding, curriculumbeschrijvingen en activiteiten binnen de faculteiten. Voorts is er een grote belangstelling voor overname van (vertaalde) topartikelen over medisch onderwijs uit buitenlandse tijdschriften. De redenen waarom bijna driekwart van de lezers de laatste 5 jaren geen manuscript ter publicatie in TMO heeft aangeboden, variëren sterk, maar zijn zelden ingegeven door een voorkeur voor een buitenlands tijdschrift boven TMO.

Discussie: De redactie wil de resultaten van het lezersonderzoek gebruiken als leidraad voor haar beleid. De belangrijkste doelgroep wordt gevormd door medici en onderwijskundigen in instellingen voor medisch-wetenschappelijk onderwijs. In een nieuwe rubriek zal de redactie meer aandacht schenken aan activiteiten en ontwikkelingen binnen de medische faculteiten c.q. universitaire medische centra. Voorts zal de redactie de mogelijkheid van dubbelpublicaties in zowel een buitenlands tijdschrift als TMO stimuleren. Om de aantrekkelijkheid van TMO als tijdschrift om in te publiceren te vergroten, zal de redactie een aanvraag indienen bij de National Library of Medicine om het tijdschrift op te nemen in de Index Medicus. (Borleffs JCC, namens de redactie. TMO beoordeeld: resultaten van het lezersonderzoek 2003. Tijdschrift voor Medisch Onderwijs 2004;23(3):153-160.)

\section{Inleiding}

In haar ruim 30-jarig bestaan heeft het Tijdschrift voor Medisch Onderwijs (TMO) een aantal keren een gedaanteverandering ondergaan. Zo is in de loop der tijd het formaat van het tijdschrift veranderd, de frequentie van verschijning, de opmaak en de omslag. Tevens is de stu- ring in de beoordelingsprocedure van ingezonden manuscripten toegenomen.

$\mathrm{Na}$ al deze veranderingen ontstond de wens om het oordeel van de lezers over TMO te vernemen. Hoe denken zij over het vernieuwde tijdschrift en wat draagt er toe bij de belangstelling voor TMO onder clinici (en klinische docenten) te 
vergroten, de inhoud van het tijdschrift nog verder te verbeteren en de belangstelling om in TMO te publiceren te doen groeien? Met hulp van de uitgever van het tijdschrift, Bohn Stafleu van Loghum (BSL), werd daarom een lezersonderzoek gehouden onder alle abonnees van het tijdschrift. In deze bijdrage brengt de redactie verslag uit van dit lezersonderzoek en geeft zij aan welke consequenties voor de ontwikkeling van TMO zij aan de resultaten van het onderzoek wil verbinden.

\section{Materiaal en methoden}

\section{Beschrijving van het lezersonderzoek}

De vragenlijst die voor het lezersonderzoek is gebruikt, is voor een belangrijk deel gebaseerd op vragenlijsten zoals die door BSL de laatste jaren met succes zijn gebruikt bij de evaluatie van het lezersoordeel over door hen uitgegeven tijdschriften. De door BSL gemaakte concept-vragenlijst is vervolgens door de redactie van het tijdschrift en het bestuur van de Nederlandse Vereniging voor Medisch Onderwijs (NVMO) beoordeeld op de relevantie voor het lezerspubliek van TMO. Voor de redactie was het belangrijk om met name het lezersoordeel over het niveau van de inhoud en lay-out van het tijdschrift te verkrijgen. Dit heeft geleid tot het herformuleren (meestal verduidelijken) en toevoegen van een aantal vragen. De 22 vragen die uiteindelijk de definitieve lijst bepaalden, konden als volgt gerubriceerd worden: vragen over het lezersprofiel (6), het soort informatie dat de lezer in TMO zoekt (1), het leesgedrag (6), de waardering voor TMO als lezer (7) en de waardering voor TMO als tijdschrift om als auteur in te publiceren (2).

De vragenlijst is eind september 2003 door de uitgever verstuurd aan alle 748 abonnees van TMO in een aparte mailing, met een begeleidend schrijven over een
Merck Manual voor iedere honderdste inzender van de vragenlijst, en een aan BSL gerichte antwoordenvelop. BSL was ook verantwoordelijk voor de verwerking van de resultaten van de teruggestuurde vragenlijsten.

\section{Resultaten}

In een periode van 4 weken zijn 254 van de 748 verstuurde vragenlijsten aan BSL geretourneerd (34\%). Omdat op de meeste vragen meerdere antwoorden mogelijk waren, is in de meeste tabellen het aantal antwoorden aanzienlijk groter dan het aantal respondenten. Tabel 1 toont de kengetallen van het lezersprofiel van de respondenten. Het merendeel van de respondenten heeft een functie in het onderwijs (docent, opleidingscoördinator, hoofd opleiding). Ruim $15 \%$ van hen heeft een medische achtergrond, bijna $10 \%$ is onderwijskundige. De meeste respondenten zijn verbonden aan een opleidingsinstituut en/of medische instelling (resp. 53.9\% en 35.4\%) met een medisch-wetenschappelijke achtergrond $(88.3 \%)$. Het percentage respondenten verbonden aan een HBO-instelling is gering (5.4\%). Veruit de meeste TMO-lezers zijn werkzaam in Nederland (97.6\%), slechts een klein deel in Vlaanderen $(2.0 \%)$. Ruim een kwart van de lezers heeft de afgelopen 5 jaren een manuscript ter publicatie in TMO aangeboden (27.4\%).

In tabel 2 is de informatiebehoefte van de lezers weergegeven. Verreweg het grootst is de belangstelling voor inhoudelijke onderwerpen op het gebied van onderwijs (onderwijskundig onderzoek en andere onderwijskundige onderwerpen, onderwijsvernieuwing in Nederland en in het buitenland). De behoefte aan meer praktische informatie (ontwikkelingen op de arbeidsmarkt, overheidsmaatregelen en vacatures) is relatief gering.

Tabel 3 presenteert enkele kenmerken van het lezersgedrag van de responden- 
Tabel 1. Lezersprofiel (bij de meeste vragen zijn meerdere antwoorden mogelijk).

\begin{tabular}{|c|c|c|c|c|}
\hline & & & Aantal & $\%$ \\
\hline \multirow[t]{18}{*}{ Opleiding/werk } & \multirow[t]{13}{*}{ Functie } & Medisch specialist & 59 & 13.3 \\
\hline & & Huisarts & 2 & 0.5 \\
\hline & & Arts-assistent & 8 & 1.8 \\
\hline & & Verloskundige & 5 & 1.1 \\
\hline & & Dierenarts & 2 & 0.5 \\
\hline & & Onderwijskundige & 41 & 9.2 \\
\hline & & Student & 9 & 2.0 \\
\hline & & Docent & 118 & 26.6 \\
\hline & & Opleidingscoördinator & 59 & 13.3 \\
\hline & & Hoofd opleiding & 33 & 7.4 \\
\hline & & Staffunctionaris & 46 & 10.4 \\
\hline & & Anders & 62 & 14.0 \\
\hline & & Totaal & 444 & \\
\hline & \multirow[t]{5}{*}{ Scholing } & VWO & 28 & 10.1 \\
\hline & & $\mathrm{HBO}$ & 9 & 3.3 \\
\hline & & WO & 120 & 43.5 \\
\hline & & Post-WO/HBO & 119 & 43.1 \\
\hline & & Totaal & 276 & \\
\hline \multirow[t]{12}{*}{ Type instelling } & \multirow[t]{5}{*}{ Functie } & Opleidingsinstituut & 160 & 53.9 \\
\hline & & Zorginstelling & 15 & 5.1 \\
\hline & & Medische instelling & 105 & 35.4 \\
\hline & & Anders & 17 & 5.7 \\
\hline & & Totaal & 297 & \\
\hline & \multirow[t]{7}{*}{ Aard } & WO medisch & 184 & 58.4 \\
\hline & & WO niet-medisch & 12 & 3.8 \\
\hline & & AGIO medisch & 82 & 26.1 \\
\hline & & HBO paramedisch & 12 & 3.8 \\
\hline & & HBO overig & 5 & 1.6 \\
\hline & & Anders & 20 & 6.3 \\
\hline & & Totaal & 315 & \\
\hline \multirow{6}{*}{\multicolumn{2}{|c|}{ Leeftijd }} & 20-30 jaar & 21 & 8.3 \\
\hline & & 31-39 jaar & 33 & 13.0 \\
\hline & & 40-49 jaar & 73 & 28.7 \\
\hline & & 50-59 jaar & 103 & 40.6 \\
\hline & & $>60$ jaar & 24 & 9.4 \\
\hline & & Totaal & 254 & \\
\hline \multirow{4}{*}{\multicolumn{2}{|c|}{ Werkzaam in }} & Nederland & 247 & 97.6 \\
\hline & & België (Vlaanderen) & 5 & 2.0 \\
\hline & & Elders & 1 & 0.4 \\
\hline & & Totaal & 253 & \\
\hline \multirow{3}{*}{\multicolumn{2}{|c|}{$\begin{array}{l}\text { Laatste } 5 \text { jaar een manuscript } \\
\text { ter publicatie in TMO } \\
\text { aangeboden }\end{array}$}} & $\mathrm{Ja}$ & 68 & 27.4 \\
\hline & & Nee & 180 & 72.6 \\
\hline & & Totaal & 248 & \\
\hline
\end{tabular}


Tabel 2. Informatiebehoefte (bij de meeste vragen zijn meerdere antwoorden mogelijk).

\begin{tabular}{lcr}
\hline Onderwerp & Aantal & $\%$ \\
\hline Onderwijskundige kennis & 211 & 20.7 \\
Resultaten onderwijskundig onderzoek & 193 & 19.0 \\
Informatie over onderwijsvernieuwing in Nederland & 188 & 18.5 \\
Trends en ontwikkelingen in het buitenland & 130 & 12.8 \\
Beroepspraktijkvorming op de werkvloer & 113 & 11.1 \\
Overheidsmaatregelen & 79 & 7.8 \\
Ontwikkelingen op de arbeidsmarkt & 31 & 3.0 \\
Vacatures & 26 & 2.6 \\
Divers & 47 & 4.6 \\
\hline Totaal & 1018 & $\mathbf{1 0 0 . 0}$ \\
\hline
\end{tabular}

Tabel 3. Leesgedrag.

\begin{tabular}{llr}
\hline Vraag & Antwoord & $\%$ \\
\hline Waar ontvangt u TMO? & Huisadres & 37.7 \\
& Werkadres & 58.8 \\
& Via roulatiesysteem & 2.3 \\
& Anders & 1.2 \\
Waar leest u TMO? & (Vooral) thuis & 67.1 \\
& (Vooral) op het werk & 32.9 \\
Hoeveel tijd besteedt u gemiddeld aan het lezen van TMO? & $<15$ minuten & 10.2 \\
& 30 minuten & 48.3 \\
& G0 minuten & 38.1 \\
Hoe/wat leest u (in) TMO? & $>60$ minuten & 3.4 \\
& Volledig & 6.6 \\
& Selectief en wisselend & 84.4 \\
Wat doet u met TMO na het lezen ervan? & Samenvattingen & 6.3 \\
& Inhoudsopgave & 2.7 \\
& Bewaren & 61.7 \\
& Aan collega geven & 8.0 \\
& In roulatiesysteem & 4.5 \\
Hoeveel andere personen lezen uw exemplaar van TMO? & Relevante artikelen aan collega geven & 18.8 \\
& Weggooien & 7.0 \\
& Geen & 57.5 \\
& 1-2 personen & 34.9 \\
& 3-5 personen & 6.0 \\
& $>5$ personen & 1.6 \\
\hline
\end{tabular}

ten. Het merendeel van de lezers besteedt gemiddeld 30-60 minuten aan TMO en leest selectief. Bij ongeveer een derde van de respondenten wordt TMO door 1-2 an- deren gelezen. Bij slechts een gering aantal abonnees circuleert het tijdschrift onder 3 of meer andere lezers. 
De waardering voor de inhoud van TMO wordt in figuur 1 weergegeven. Voor alle parameters van de waardering zijn de categorieën 'redelijk' en 'gemiddeld' het meest vertegenwoordigd. De categorieën 'sterk', 'redelijk' en 'gemiddeld' tezamen genomen, laat zien dat $93.1 \%$ van de lezers TMO informatief vindt, dat voor $75.8 \%$ de inhoud toepasbaar is in de praktijksituatie en dat $82.8 \%$ de inhoud voldoende diepgaand en $86.6 \%$ de inhoud vernieuwend vindt. De enige parameter die relatief laag scoort is de uitdaging van TMO tot interactie. Slechts $35.8 \%$ is daarover tevreden en $64.2 \%$ niet of nauwelijks. Het gemiddelde 'rapportcijfer' dat de lezers aan TMO geven, is 7.1 , met $82.1 \%$ die een 7 of hoger geeft. Wat betreft de verschillende rubrieken van TMO krijgen onderzoek, overzichtsartikelen, beschouwende artikelen en onderwijs in de praktijk de grootste waardering (tabel 4). De andere rubrieken zijn minder aansprekend.
Tabel 4. Voorkeur voor rubrieken van TMO (in de vragenlijst waren meerdere antwoorden mogelijk).

\begin{tabular}{lcc}
\hline Rubriek & Aantal & $\%$ \\
\hline Onderzoek & 184 & 18.6 \\
Overzichtsartikelen & 171 & 17.3 \\
Beschouwingen & 152 & 15.4 \\
Onderwijs in de praktijk & 188 & 19.0 \\
Bespreking van studieboeken & 40 & 4.0 \\
Boekbesprekingen & 55 & 5.6 \\
Referaten & 29 & 2.9 \\
Congresverslagen & 42 & 4.2 \\
Ingezonden brieven & 31 & 3.1 \\
NVMO mededelingen & 39 & 3.9 \\
Redactionele artikelen & 59 & 6.0 \\
\hline Totaal & 990 & 100.0 \\
\hline
\end{tabular}

De waardering voor de vormgeving van TMO is in figuur 2 weergegeven. De categorieën 'sterk', 'redelijk' en 'gemiddeld' tezamen genomen vindt $89.3 \%$ van de lezers TMO uitnodigend om te lezen, vindt $96.5 \%$ het tijdschrift prettig leesbaar

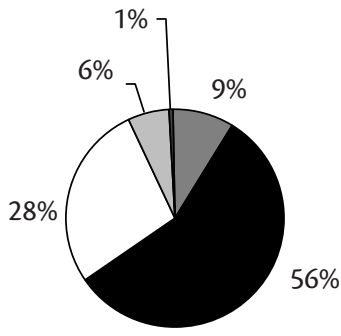

Informatief

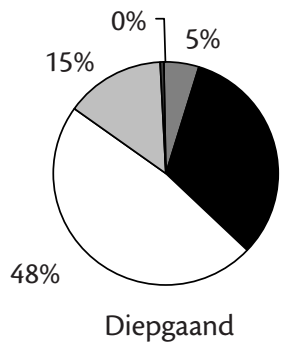

$32 \%$
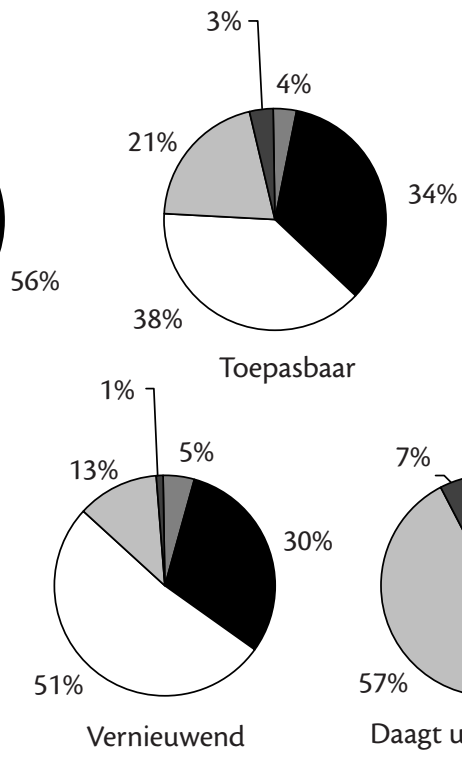

$4 \%$
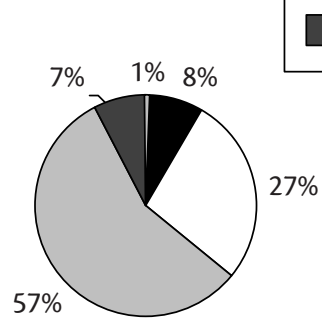

Daagt uit tot interactie

Figuur 1. Waardering voor de inhoud van TMO. 


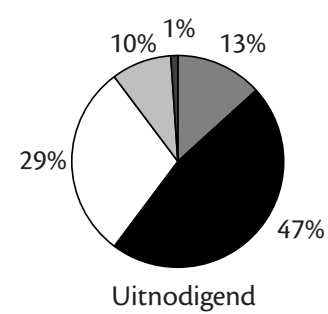

Uitnodigend

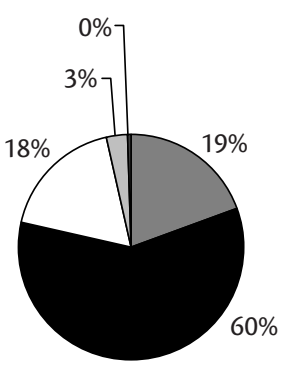

Prettig leesbaar

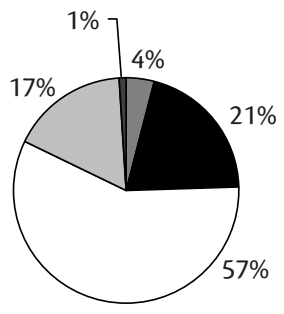

Formeel

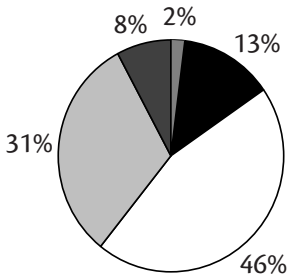

Goed geillustreerd

Sterk

Redelijk

Gemiddeld

Nauwelijks

Niet

Figuur 2. Waardering voor de vormgeving van TMO.

en vindt $82.5 \%$ de vormgeving formeel. Over de illustraties (tabellen en figuren) is $61 \%$ van de lezers tevreden en $39 \%$ minder tot niet tevreden.

Een belangrijke vraag in de enquête is, waar lezers meer over zouden willen lezen (tabel 5). Informatie over activiteiten binnen de faculteiten en curriculumbeschrijvingen scoren daarbij relatief hoog (tezamen $40 \%$ ). Voorts is er een grote belangstelling voor bijdragen over de medisch specialistenopleiding en voor overname van (vertaalde) topartikelen over medisch onderwijs uit buitenlandse tijdschriften (resp. $15.6 \%$ en $23.1 \%$ ).

Tabel 5. Voorkeursonderwerpen van lezers (in de vragenlijst waren meerdere antwoorden mogelijk).

\begin{tabular}{lrr}
\hline Onderwerp & Aantal & $\%$ \\
\hline Lopende activiteiten in de & 133 & 20.7 \\
faculteiten & & \\
Curriculumbeschrijvingen & 111 & 17.3 \\
Medisch specialistenopleiding & 100 & 15.6 \\
Andere dan medische opleidingen & 25 & 3.9 \\
Onderwijsbeleid & 94 & 14.6 \\
(Vertaalde) topartikelen over & 148 & 23.1 \\
medisch onderwijs in & & \\
buitenlandse tijdschriften & & \\
\hline Totaal & $\mathbf{6 1 1}$ & $\mathbf{1 0 0 . 0}$ \\
\hline
\end{tabular}

Zoals in tabel 1 is weergegeven, heeft bijna driekwart van de lezers de laatste 5 jaren geen manuscript ter publicatie in TMO aangeboden. Uit de individuele opmerkingen van de respondenten worden in het merendeel der gevallen 'werk nog niet lang in huidige baan', 'tijdgebrek' en 'geen relevant onderzoek verricht' als argument daarvoor aangevoerd. Bij 11 van de 180 lezers $(6 \%)$ die de laatste 5 jaren geen manuscript bij TMO hebben ingediend, speelt de voorkeur voor een buitenlands tijdschrift boven TMO een rol.

\section{Discussie}

Bij de evaluatie van een lezersonderzoek is de representativiteit van de verkregen gegevens een belangrijk punt. Bij het lezersonderzoek onder TMO-abonnees was de respons $34 \%$. In vergelijking met de respons bij andere lezersonderzoeken, die meestal rond de $20 \%$ ligt, is dit een uitzonderlijk goede respons (Bohn Stafleu van Loghum, persoonlijke mededeling). Ofschoon dit niets zegt over de mate van representativiteit van de respondenten voor het lezerspubliek van TMO, nemen we toch aan dat een respons van $34 \%$ een goede basis vormt voor een lezersoordeel over TMO. 
In het algemeen is men tevreden over zowel de inhoud als de vormgeving van TMO. Meer dan $80 \%$ van de lezers geeft TMO een 7 of hoger als rapportcijfer. Vanzelfsprekend is de redactie verheugd over dit positieve oordeel en beschouwt zij dit als een stimulans om de enkele jaren geleden ingeslagen weg van veranderde opzet en vormgeving van TMO voort te zetten. Omdat ruim een derde van de lezers vindt dat de duidelijkheid van de tabellen en figuren niet optimaal is, zal de redactie proberen dit aspect van de vormgeving te verbeteren. Voorts zal de redactie het inzenden van ingezonden brieven als reactie op gepubliceerde artikelen meer stimuleren om de door de lezers aangegeven gebrekkige uitdaging tot interactie te vergroten.

Het lezersonderzoek maakt duidelijk dat medici, onderwijskundigen en anderen werkzaam in of betrokken bij instellingen voor medisch-wetenschappelijk onderwijs en opleiding de grootste lezersgroep vormen. De redactie is van mening dat deze categorie lezers ook in de toekomst de belangrijkste doelgroep van TMO dient te blijven. De uitgave van een 'specialistennummer' als eerste nummer van 2004 is een voorbeeld van het streven van de redactie om TMO aantrekkelijker te maken voor medisch specialisten. De bevinding van het lezeronderzoek dat er behoefte is aan meer bijdragen over de medisch specialistische vervolgopleiding ondersteunt dit beleid.

Daarnaast laat het lezersonderzoek zien dat er behoefte bestaat aan meer informatie over activiteiten en ontwikkelingen binnen de medische faculteiten c.q. universitaire medische centra. De redactie zal dit ter harte nemen en er in een nieuwe rubriek meer aandacht aan schenken. Tenslotte blijkt er belangstelling te zijn voor overname van vertaalde topartikelen over onderwijskundige onderwerpen uit buitenlandse tijdschriften. Ook hiervoor geldt dat de redactie zal proberen om aan deze wens tegemoet te komen door het stimuleren van dubbelpublicaties van artikelen van Nederlandse auteurs in buitenlandse tijdschriften.

Een belangrijke vraag is hoe aantrekkelijk TMO is voor potentiële auteurs. Het onderzoek toont aan dat de meerderheid van de lezers de laatste 5 jaren geen manuscript ter publicatie heeft aangeboden. Ofschoon de reden niet lijkt te zijn dat TMO 'onvoldoende aantrekkelijk' is, wil de redactie ook aan dit aspect aandacht schenken. Een belangrijke stap daartoe is het indienen van een aanvraag bij de National Library of Medicine in de Verenigde Staten tot opname van TMO in de Index Medicus.

Concluderend heeft het lezersonderzoek de redactie veel nuttige informatie opgeleverd. De waardering voor TMO is een grote stimulans en de inventarisatie van de wensen van de lezers een goede leidraad voor het uitzetten van toekomstig redactioneel beleid.

\section{De auteur:}

Dr. J.C.C. Borleffs is internist en directeur opleidingen van het Onderwijsinstituut van het Universitair Medisch Centrum Utrecht. Voorts is hij hoofdredacteur van het Tijdschrift voor Medisch Onderwijs.

Correspondentieadres:

Dr. J.C.C. Borleffs, Onderwijsinstituut, Universitair Medisch Centrum, Universiteitsweg 100, 3584 CG Utrecht, j.c.c.borleffs@med.uu.nl. 


\section{Summary}

Introduction: After the introduction of changes in the Dutch Journal of Medical Education (TMO) as regards format, publication rate, lay-out, cover and review process, the editorial board wanted to evaluate the results of those changes.

Material and methods: In the autumn of 2003 a survey was conducted among the readership of TMO. TMO readers were asked to complete and return a written questionnaire consisting of 22 questions about reader profile, the type of information readers look for in TMO, the way they read TMO and their appreciation of TMO as a reader and as a potential author.

Results: Of 748 questionnaires, 254 were completed and returned. The mean appreciation on a scale from 1-10 was 7.1, which is quite satisfactory. Most readers indicated that they saw TMO as an informative journal and considered the articles useful for educational practice as well as adequate as regards depth and innovative aspects. The majority of the readers were interested in articles on educational research, innovation, postgraduate specialty training, curriculum descriptions and activities within the medical schools. There was also considerable interest in (translated) important articles from the international medical education literature. A variety of reasons for not submitting papers to TMO were given by almost three quarters of the respondents, who did not do so. The reasons were almost never related to a preference for publishing in an international journal.

Discussion: The editorial board intend to use the outcomes of the readership survey to guide their editorial policies. TMO's main target group are doctors and educationalists in institutes for medical scientific education. A new section will focus specifically on activities and developments within the medical schools and academic medical centres. The editors also want to encourage double publication of articles in international journals and TMO. In order to make TMO more attractive to prospective authors an application will be lodged with the National Library of Medicine to include TMO in the Index Medicus. (Borleffs JCC, on behalf of the Editorial Board. An evaluation of the Dutch Journal of Medical Education: results of a readership survey in 2003. Dutch Journal of Medical Education 2004;23(3):153-160.) 